\title{
Inhibitory effect of plant extracts on the cytotoxicity of eurytele nematocysts from Pelagia noctiluca
}

\author{
Rossana Morabito, ${ }^{1}$ Laura Cornara, ${ }^{2}$ Giuseppina La Spada, ${ }^{1}$ Angela Marino, ${ }^{1}$ Gian Luigi Mariottini, ${ }^{2}$ \\ Alessia Remigante, ${ }^{1}$ Bruno Burlando ${ }^{3}$ \\ ${ }^{1}$ Department of Chemical, Biological, Pharmaceutical and Environmental Sciences, University of Messina, Messina; \\ ${ }^{2}$ Department of Earth, Environment and Life Sciences, University of Genova, Genova; ${ }^{3}$ Department of Pharmacy, \\ University of Genova, Genova, Italy
}

\begin{abstract}
Some species of Cnidarians, well known venomous organisms, are able to induce serious health problems as well as economic and social trouble. A lot of data show that cnidarian venoms can be cytotoxic to cultured cells. Therefore, a priority of the research is to find tools which could counteract the damaging activity of venoms. In this connection, the modulatory effects exerted by extracts of plants Ananas comosus (L.) and Carica papaya (L.) on cytotoxicity of heterotrichous microbasic eurytele nematocysts isolated from the jellyfish Pelagia noctiluca was evaluated. The nematocyst extract induced strong cytotoxicity at highest tested doses with reduction of cell survival below $40 \%$ and $\mathrm{IC}_{50}$ value of $40 \times 10^{3}$ nematocysts $/ \mathrm{mL}$. Both plant extracts significantly improved the survival of cells, so that the $\mathrm{IC}_{50}$ resulted
\end{abstract}

Correspondence: Gian Luigi Mariottini, Department of Earth, Environment and Life Sciences, University of Genova, Corso Europa 30,16132 , Genova, Italy.

Tel.: +390103538070; Fax: +390103538072.

E-mail: Gian.Luigi.Mariottini@unige.it; glmariottini@libero.it

Key words: Jellyfish; nematocysts; cytotoxicity; plant extracts; venom inactivation.

Acknowledgements: We are grateful to Dr. Antonio Daga of IRCCS San Martino Hospital, Genova, for kindly placing the ultrasonic disintegrator at our disposal, and to Dr. Mario Nizzari of the Pharmacology Section of the Department of Internal Medicine, University of Genova, for his help in microplates reading.

Conflict of interest: the authors declare no potential conflict of interests.

Received for publication: 26 May 2020.

Accepted for publication: 20 September 2020.

${ }^{\circ}$ Copyright: the Author(s), 2020

Licensee PAGEPress, Italy

Journal of Biological Research 2020; 93:9136

doi:10.4081/jbr.2020.9136

This article is distributed under the terms of the Creative Commons Attribution Noncommercial License (by-nc 4.0) which permits any noncommercial use, distribution, and reproduction in any medium, provided the original author(s) and source are credited.
$74 \times 10^{3}$ and $100 \times 10^{3}$ nematocysts $/ \mathrm{mL}$ in the presence of $A$. comosus and C. papaya extracts, respectively, both used at 10 and 100 $\mu \mathrm{g} / \mathrm{mL}$. Taking into account that heterotrichous microbasic eurytele nematocysts are present mainly in tentacles, which Pelagia noctiluca utilizes both for predation and defence, this result is particularly interesting from both ecological and sanitary point of view and demonstrates the potential of these plants extracts against cnidarian venoms.

\section{Introduction}

The toxicity of marine cnidarians is a subject of concern, being venoms from coral, anemones, and jellyfish well known for their activity to human skin, cytotoxicity to cells, as well as for lethal accidents occurring in coastal zones. ${ }^{1}$ In fact, in addition to the irritant activity, Cnidarian venoms can induce serious consequences such as extensive dermonecrosis, neurotoxicity and cardiotoxicity, with variable outcomes according to the stinging species and the sensitivity of stung subjects. ${ }^{2}$ Other negative effects are exerted on ecosystems, aquaculture, coastal industrial activities, and fisheries, including the influence on fish stocks due to predation on early life stages of fish, as well as competition for food. ${ }^{3}$

During the last decades, cnidarian (mainly jellyfish) outbreaks have occurred with high incidence everywhere, induced by several still unknown causes, among which climate change seems to play a remarkable role. ${ }^{4}$ As a consequence, jellyfish outbreaks represent a global sanitary and economical problem in coastal waters, especially in areas hosting species that can cause serious toxicity and death.

Several studies have reported haemolytic properties, ${ }^{5}$ as well as cytotoxic effects to different cultured cells ${ }^{6}$ exerted by various Mediterranean jellyfish. The possibility of inactivating venom by using biological sources is an interesting aspect for pharmacological and therapeutic purposes. Hence, various studies have been directed to investigate plant extracts known to be protective against venomous animals, such as snakes, ${ }^{7}$ scorpions,${ }^{8}$ and jellyfish. ${ }^{9}$

This work is aimed at evaluating the modulatory effects exerted by plant extracts on Heterotrichous Microbasic Eurytele (HME) nematocysts isolated from the venomous Mediterranean jellyfish, Pelagia noctiluca (Cnidaria, Scyphozoa, Pelagiidae), popularly known as the "mauve stinger". ${ }^{10}$ Two plant species, viz. Ananas comosus (L.) Merr. (Bromeliaceae) and Carica papaya L. (Caricaceae), whose extracts are known for their activity against animal venoms, ${ }^{7}$ have been considered as a source of anti-venom compounds. 
The pineapple, A. comosus, is native to Central America and currently grows in warm regions worldwide. Fruits contain bromelain, a proteolytic enzyme, and other proteases such as chimotrypsin and trypsin. ${ }^{11}$ Bromelain is a mixture of enzymes (cysteine proteases) having anti-oedematous, anti-inflammatory (preventing inflammatory signalling), anti-coagulant (fibrinolytic, anti-thrombotic) ${ }^{12}$ and immunomodulatory (increasing monocyte response against cancer cells and inducing $\alpha$-TNF, IL-1, IL-6, IL8 production $)^{13}$ properties. This plant is widely used in traditional medicine for the care of digestive problems, wounds, bruising, burns, oedema, and pain to joints. ${ }^{9}$

Carica papaya is a small tree typical of Southern Mexico and Costa Rica, but also growing in Australia, Hawaii, South Africa, Philippines, Sri Lanka, India, and other tropical and sub-tropical areas. ${ }^{14}$ The fruit contains four main cysteine endopeptidases, namely papain, chymopapain, glycine endopeptidase, and caricain. ${ }^{15}$ Other enzymes are also present, such as lysozyme, chitinases, serine proteinase inhibitor, and glutaminyl-cyclo transferase, ${ }^{16}$ and alkaloids with stimulating properties on the central nervous system. Fruit extracts are known to have antimicrobial, anti-inflammatory, anti-ulcers, immunomodulatory, anthelmintic, and aphrodisiac properties. The plant is largely utilized in pharmaceutical and food industries; ${ }^{17}$ papain is a cosmetic ingredient ${ }^{18}$ and is also known for inactivating animal venoms. ${ }^{19}$

We carried out experiments for testing the effects of crude venom from $P$. noctiluca HME nematocysts on cultured L929 mouse fibroblasts, in the presence or absence of extracts from the above plant species. A twofold objective was strived for: i) evaluation of the cytotoxic properties of the venom contained in HME nematocysts; ii) inactivation of venom cytotoxicity induced by coincubation of cells with plant extracts.

\section{Materials and Methods}

\section{Jellyfish sampling and nematocyst isolation}

Specimens of $P$. noctiluca were sampled in the Strait of Messina (Italy). After capture, jellyfish were put in tanks containing seawater at room temperature and transferred to the laboratory, where tentacles were immediately excised and frozen at $-20^{\circ} \mathrm{C}$ until use. The isolation of undischarged HME nematocysts, which are known to be mainly contained in tentacles, was carried out according to Salleo et al. ${ }^{20}$ Briefly, tentacles were put in distilled water for $2 \mathrm{~h}$ at $4{ }^{\circ} \mathrm{C}$ to induce nematocyst release by osmotic lysis and subjected to stirring to induce the release of nematocysts attached to the epidermal tissue. The underlying tissue was removed from nematocysts by repeated washing of the suspension in distilled water and filtration through a series of plankton nets: 100,60 and $40 \mu \mathrm{m}$ mesh. The suspension was then centrifuged at $4^{\circ} \mathrm{C}$ (4000' $\mathrm{g}$ for $5 \mathrm{~min}$ ) to remove residual debris, and then the supernatant containing HME nematocysts was lyophilized and maintained at $-20{ }^{\circ} \mathrm{C}$ until use.

\section{SEM analysis}

Samples of nematocysts were fixed in FineFix formalin substitute (Milestone Medical, Sorrisole, BG, Italy), dehydrated through a series of ethanol up to $100 \%$, and critical point dried. Subsequently, samples were mounted in aluminum stubs, covered with bi-adhesive carbon dishes, and sputtered with $10 \mathrm{~nm}$ gold film. SEM observations were carried out by using a Vega3 TESCAN type LMU Scanning Electron Microscope, provided with X- ray EDS APOLLO XSD energy dispersion system (Tescan Inc., PA, USA).

\section{Venom extraction from nematocysts}

Lyophilized nematocysts were re-suspended in $1 \mathrm{ml}$ deionized water and counted in Thoma hemocytometer under an optical microscope Leica Mod DM2000 (Leica Microsystems, Buccinasco, MI, Italy). Subsequently, venom was extracted from nematocysts according to Arillo et al. ${ }^{21}$ using an ultrasonic disintegrator (Cellai Soniprep) in ice bath for $45 \mathrm{~min}$, by alternating 30 sec sonication and $30 \mathrm{sec}$ breaks to avoid sample heating. Finally, the sample was centrifuged at $4000 \mathrm{rpm}$ to remove residual debris, and the supernatant was collected and filtered by using low-protein retention $0.2 \mu \mathrm{m}$ filters (Millipore).

\section{Preparation of plant extracts}

Dried aqueous extracts of $A$. comosus fruit stem, and $C$. papaya fruit were acquired from the Istituto Farmochimico Fitoterapico S.r.l. (Milano, Italy). Extracts were re-suspended in water, filtered through $0.2 \mu \mathrm{m}$ filters (Millipore), and stock solutions of $200 \mathrm{mg} / \mathrm{mL}$ were prepared in DMEM containing $10 \%$ DMSO.

Preliminary cell viability tests with either A. comosus or $C$. papaya extracts only were performed to evaluate the cytotoxicity of plant extracts to L929 cells.

\section{Cell cultures, and cell viability assays}

L929 mouse fibroblasts, were purchased from the Istituto Zooprofilattico Sperimentale della Lombardia e dell'EmiliaRomagna (Brescia, Italy), and maintained in a humidified incubator at $5 \% \mathrm{CO}_{2}$, in DMEM supplemented with 5\% FBS, $1 \%$ penicillin $(100 \mathrm{U} / \mathrm{mL}), 1 \%$ streptomycin $(100 \mu \mathrm{g} / \mathrm{mL})$, and $1 \%$ L-glutamine (EuroClone, Pero, MI, Italy). Fibroblasts were chosen as experimental model because they are an important component of the dermal tissue that is a main target of jellyfish venom, due to the penetration power of nematocysts. Furthermore, fibroblasts are involved in inflammatory responses, so that they are a suitable model for studies on skin irritation and contact dermatitis.

Cell viability was determined by the MTT assay. Aliquots of 20,000 cells per well were settled in 96-well plates and preliminary MTT assessment of plant cytotoxicity was carried out by exposing cells for $48 \mathrm{~h}$ to increasing concentrations (0 to $2,000 \mu \mathrm{g} / \mathrm{mL}$ ) of each extract (DMSO final concentrations below $0.1 \%$ ), in order to identify subtoxic extract doses. Subsequently, cells were exposed for $48 \mathrm{~h}$ to crude venom deriving from increasing numbers of nematocysts $\left(7.5 \times 10^{3}, 15 \times 10^{3}, 30 \times 10^{3}, 75 \times 10^{3}\right.$, and $\left.150 \times 10^{3}\right)$ in the absence or presence of previously determined subtoxic concentrations (10 and $100 \mathrm{mg} / \mathrm{mL}$ ) of plant extracts, chosen on the basis of results of cytotoxicity tests (MTT assay) on L929 cells. Treated cells were then processed for MTT assay and plates were read at $570 \mathrm{~nm}$ in a BioTek microplate reader (BioTek Instruments, Winooski, VT, USA).

\section{Statistical analysis}

Data were analyzed through non-linear regression by applying the following model:

$$
\mathrm{Y}=100 \times \mathrm{T} /(1+\exp (-\mathrm{S} \times(\log (\mathrm{A})-\log (\mathrm{I}))))
$$

where: $\mathrm{Y}=$ percent cell viability in relation to control; $\mathrm{T}=$ maximum cell viability; $\mathrm{S}=$ Hill's coefficient; $\mathrm{I}=\mathrm{IC}_{50} ; \mathrm{A}=$ concentration of the cytotoxic agent. 
The analysis allowed to derive $\mathrm{IC}_{50}$ values with $95 \%$ confidence limits.

\section{Results}

Figure 1 shows the morphology and the size of a typical HME nematocyst isolated from Pelagia noctiluca and observed under light microscopy.

Figure 2 shows a SEM image of a HME nematocyst. The body of the nematocyst is well recognized; the nematocyst is discharged (or in discharging), as the first part of the filament can be seen.

Data about the cytotoxicity of $A$. comosus and $C$. papaya extracts on L929 cells are shown in Figures 3 and 4, respectively. Both extracts induced very low effects, so that the exact determination of $\mathrm{IC}_{50}$ values was not possible, but their values could be estimated at higher than $2000 \mu \mathrm{g} / \mathrm{mL}$.

The cytotoxicity induced by different doses of the venom from HME nematocysts of $P$. noctiluca and the protection activity exerted by co-incubation with $A$. comosus extract at 10 and $100 \mu \mathrm{g} / \mathrm{mL}$ are shown in Figure 5. The venom from jellyfish nematocysts induced quite strong cytotoxicity at the highest tested dose $\left(75 \times 10^{3}\right.$ nematocysts $/ \mathrm{mL}$ ) with a reduction of cell survival below $40 \%$, while in the presence of plant extracts the improving of the $\mathrm{IC}_{50}$ value was observed (Table 1). The protection effect can be considered slightly significant, as demonstrated by the $\mathrm{IC}_{50}$ confidence intervals (Table 1).

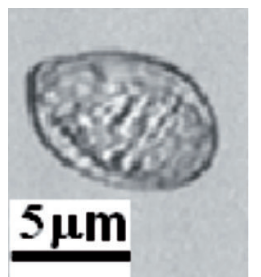

Figure 1. Microscopy image showing the morphology and size of an undischarged HME nematocyst from tentacles of Pelagia noctiluca. Note the tubule coiled inside the capsule.

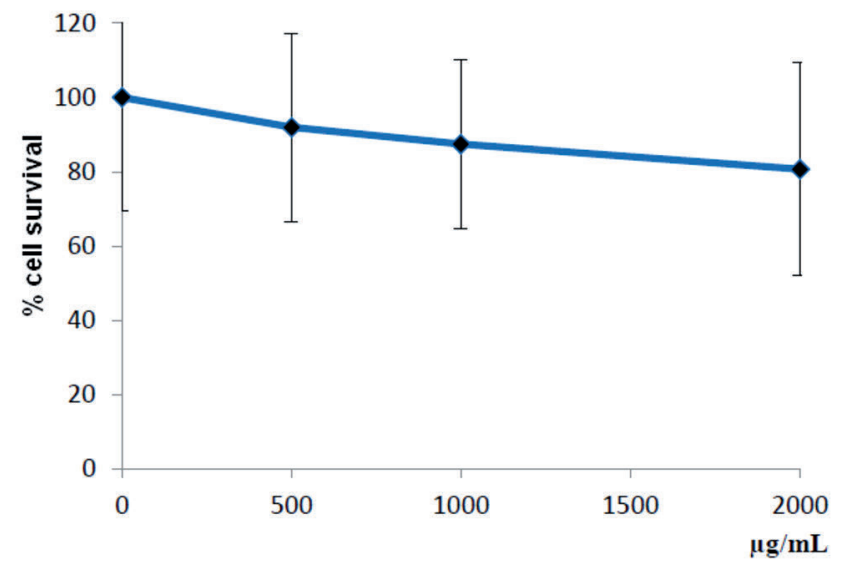

Figure 3. Cytotoxicity of $A$. comosus extract on L929 cells after 48 $h$ exposure. Data are expressed as percent variation in comparison to the control.

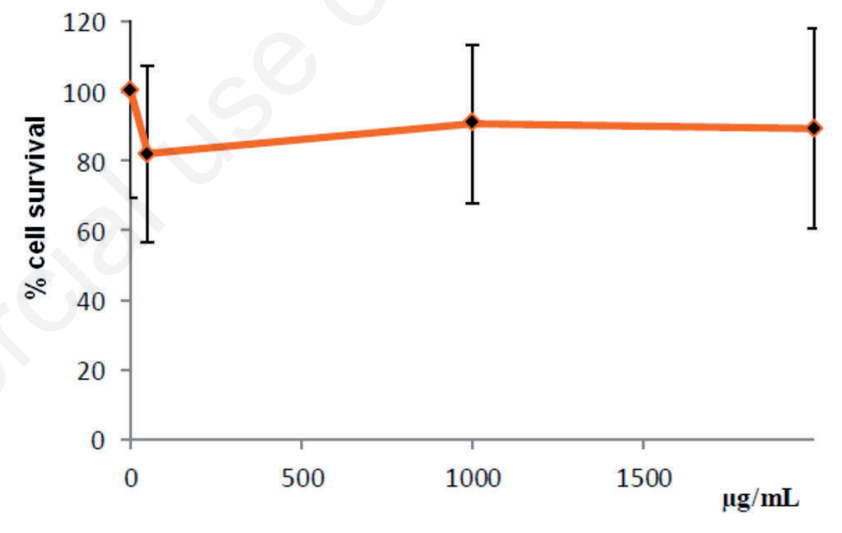

Figure 4. Cytotoxicity of $C$. papaya extract on L929 cells after 48 $h$ exposure. Data are expressed as percent variation in comparison to the control.

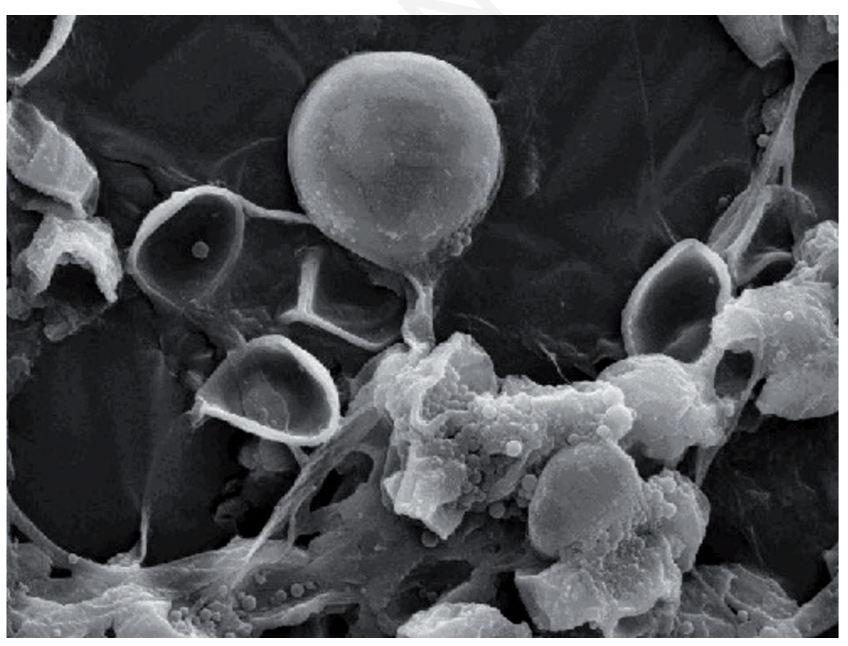

Figure 2. SEM image of a discharged HME nematocyst of Pelagia noctiluca.

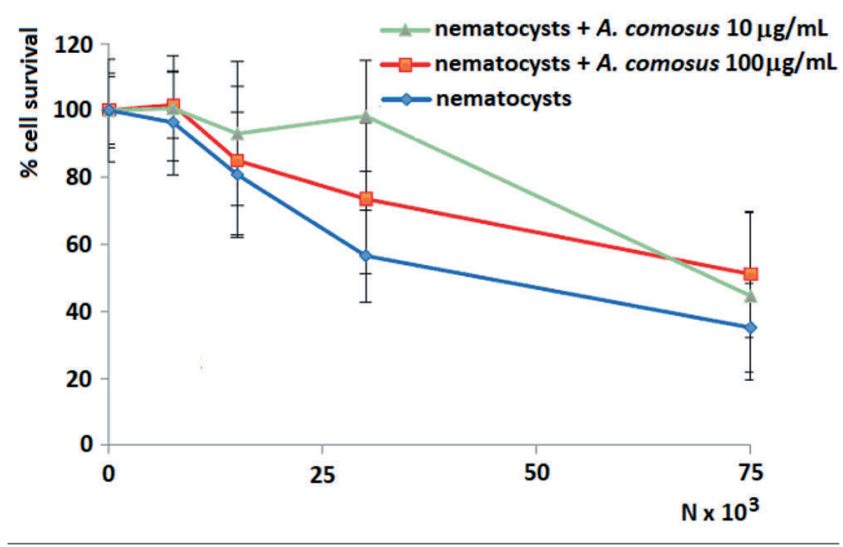

Figure 5. Cytotoxicity at $48 \mathrm{~h}$ on L929 fibroblasts of venom from HME nematocysts of Pelagia noctiluca and protection activity of the extract from Ananas comosus $(10$ and $100 \mu \mathrm{g} / \mathrm{mL})$. N: nematocysts number. 
Figure 6 shows the cytotoxicity induced by different doses of the venom from HME nematocysts of $P$. noctiluca and the protection activity exerted by co-incubation with $C$. papaya extract at 10 and $100 \mu \mathrm{g} / \mathrm{mL}$. The activity of the extract from jellyfish nematocysts alone (without addition of plant extracts) was evaluated till the dose of $150 \times 10^{3} \mathrm{~N} / \mathrm{mL}$, which induced no further increasing of cell death in comparison to the $75 \times 10^{3} \mathrm{~N} / \mathrm{mL}$ dose. Moreover, the extract from C. papaya also counteracted the jellyfish venom with an evident effect starting from low doses of venom. On the contrary, the protective effect disappeared at the highest dose of nematocyst extract. The protection exerted by $C$. papaya extract was highly significant, as shown by the shift in $\mathrm{IC}_{50}$ values and their $95 \%$ confidence intervals (Table 1 ).

\section{Discussion}

Many popular treatments are reported in the traditional medicine to fight against animal venoms and toxins, including first aid care of jellyfish stings, but they are often anecdotal and inadequate to provide an effective relief and care. ${ }^{22}$ In fact, in most of cases this empirical knowledge is scarcely transferable to pharmacological studies and industrial processes, due to the scarce clarity of the mechanisms of action, to the difficulty of using these remedies as pharmaceutical ingredients, to the occurrence

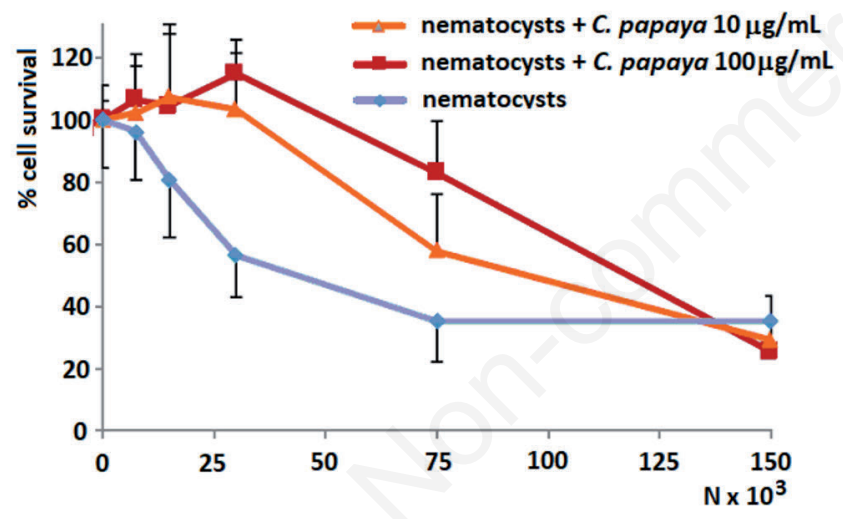

Figure 6. Cytotoxicity at $48 \mathrm{~h}$ on L929 fibroblasts of venom from HME nematocyst of Pelagia noctiluca and protection activity of the extract from Carica papaya (10 and $100 \mu \mathrm{g} / \mathrm{mL})$. N: nematocyst number. of undesired by-products, as well as for their scarce effectiveness in several cases. For all these reasons, investigating new products and active principles on a strict scientific basis is mandatory to have a good knowledge about the mechanisms of toxicity and to provide for counteracting measures.

On these premises, taking into account that cnidarians - and notably jellyfish - are an important trouble for working and recreational activities in coastal zones, the development of useful products having protective properties against their toxins could be an interesting subject for the pharmacological research.

This study shows for the first time the cytotoxic activity of venom from HME nematocyst isolated from the capsule fluid of P. noctiluca on L929 fibroblasts. This result is particularly interesting both from an ecological and a sanitary point of view, taking into account that this kind of nematocysts occurs mainly in tentacles, which are notoriously the main tool utilized by jellyfish to catch preys. These nematocysts are a well-known cause of burning and irritant phenomena after stinging to human skin. ${ }^{23}$ In this context, we must also consider that fibroblasts can be thought as a reliable cell model to study the effects of nematocysts on epithelial and dermal tissues. ${ }^{24}$

The present data show that extracts from $A$. comosus and $C$. papaya are able to protect cells against injury induced by nematocyst venom from the jellyfish $P$. noctiluca, which is known to be cytotoxic, ${ }^{25}$ with the extract from $C$. papaya showing a remarkable activity already at low concentrations, suggesting that this plant could be interesting for anti-venom applicative purposes.

Bromelain, the active principle found in $A$. comosus, is known to induce inhibitory effects (presumptively independent from the proteolytic activity) on metastatic diffusion and on platelet aggregation associated to metastasis in laboratory animals, ${ }^{12}$ as well as on intestinal motility. ${ }^{26} \mathrm{~A}$ recent study ${ }^{27}$ showed the cytotoxic effects of bromelain on four human cancer cell lines and pointed out the involved mechanism of action, which is linked to the inhibition of cancer cell growth, to the dose-dependent induction of apoptosis, to the cleavage of p53 protein, to the activity to the $\mathrm{Bcl} 2$ factor and the hyperexpression and glycosylation of the oncoprotein MUC1. ${ }^{28}$ Furthermore, both bromelain and papain have been indicated to be useful to neutralize snake venom proteins. ${ }^{7}$ Papain, which is reported to be used in traditional medicine for several uses, is known also to break down pro-inflammatory peptides and venom toxins; ${ }^{19,29}$ the inactivation of venoms seems to occur mainly when papain is experimentally mixed with venom before treatment. ${ }^{30}$

Our data could reveal significant aspects for the use of active principles as protective agents in pharmaceutical products. Plant extracts can act differently against jellyfish venom, showing a wide range of outcomes from protection to exacerbation of

Table 1. $\mathrm{IC}_{50}$ values $\left(\mathrm{N} \times 10^{3} / \mathrm{mL}\right)$ and Confidence Intervals $(\mathrm{CI})$ obtained after treatment of L929 cells with HME nematocyst venom from Pelagia noctiluca, and protection exerted by co-incubation with Ananas comosus or Carica papaya extracts. N: nematocyst number.

\begin{tabular}{lccc} 
Treatment & $\mathrm{IC}_{50}(\mathrm{~N} \times \mathbf{1 0} \mathbf{3} / \mathrm{mL})$ & $\mathrm{CI} 95 \%$ lower & \\
P. noctiluca & 40 & 29 & 56 \\
P. noctiluca + A. comosus $10 \mu \mathrm{g} / \mathrm{mL}$ & 74 & 40 & 136 \\
P. noctiluca + A. comosus $100 \mu \mathrm{g} / \mathrm{mL}$ & 72 & 45 & 116 \\
\hline P. noctiluca + C. papaya $10 \mu \mathrm{g} / \mathrm{mL}$ & 100 & 80 & 125 \\
P. noctiluca + C. papaya $100 \mu \mathrm{g} / \mathrm{mL}$ & 112 & 90 & 139 \\
\hline
\end{tabular}


venom effects. ${ }^{9}$ This is possibly due to a very complex set of interactions between different phytocomplexes and the chemical composition of cnidarian venoms, which is presumptively quite different among different species. For all these reasons the need of carrying out bio-driven fractionations focused to identify bioactive fractions in extracts is to be considered for future studies, with the perspective to identify the most active fractions. The chosen fractions could also be opportunely combined in order to obtain mixtures that could guarantee an effective wide-spectrum protection against cnidarian (and presumptively other) venoms, being also devoid of harmful effects.

Therefore, a great impulse of the research is required with a twofold perspective: i) to find and evaluate new compounds or new systems/methods of treatment, and ii) to re-evaluate the available systems/methods/compounds of treatment in order to reach a wide agreement between the researchers to give a good support to the operators in the field. The presented data provide useful indications for pharmaceutical studies focused at the development of protective products against cnidarian venoms.

\section{Conclusions}

The data reported in this study could be useful for a possible future use of selected plant extracts as a remedy against jellyfish stings. In this regard, in vitro studies on cultured cells represent the first step of a research aimed at choosing and characterizing new useful active principles.

\section{References}

1. Montgomery L, Seys J, Mees J. To pee, or not to pee: A review on envenomation and treatment in European jellyfish species. Mar Drugs 2016;14:127.

2. Tibballs J, Yanagihara AA, Turner HC, Winkel K. Immunological and toxinological responses to jellyfish stings. Inflamm Allergy Drug Targets 2011;10:438-46.

3. D'Ambra I, Malej A. Scyphomedusae of the mediterranean: state of the art and future perspectives. CNS Agents Med Chem 2015;15:81-94.

4. Purcell JE. Climate effects on formation of jellyfish and ctenophore blooms: a review. J Mar Biol Ass UK 2005;85: 461-76.

5. Marino A, Morabito R, Pizzata T, La Spada G. Effect of various factors on Pelagia noctiluca (Cnidaria, Scyphozoa) crude venom-induced haemolysis. Comp Biochem Physiol A 2008;151:144-9.

6. Marino A, Morabito R, La Spada G. Toxicity of crude venom from the Scyphozoan Pelagia noctiluca. Comp Biochem Physiol 2009; 154:S21.

7. Gomes A, Das R, Sarkhel S, et al. Herbs and herbal constituents active against snake bite. Indian J Exp Biol 2010;48:865-78.

8. Al-Asmari A, Manthiri RA, Abdo N, et al. Saudi medicinal plants for the treatment of scorpion sting envenomation. Saudi J Biol Sci 2017;24:1204-11.

9. Cornara L, Mariottini GL, Giordani P, et al. Modulatory activities of plant extracts on jellyfish cytotoxicity. Wilderness Environ Med 2020;31:266-72.
10. Mariottini GL, Giacco E, Pane L. The Mauve Stinger Pelagia noctiluca (Forsskål, 1775). Distribution, ecology, toxicity and epidemiology of stings. A review. Mar Drugs 2008;6: 496-513.

11. Bruni A, Nicoletti M. Dizionario ragionato di botanica e di fitoterapia. Piccin Nuova Libraria S.p.A, Padova, 2003.

12. Pavan R, Jain S, Shraddha, Kumar A. Properties and therapeutic application of bromelain: a review. Biotechnol Res Int 2012;976203.

13. Maurer HR. Bromelain: biochemistry, pharmacology and medical use. Cell Mol Life Sci 2001;58:1234-45.

14. Krishna KL, Paridhavi M, Patel JA. Review on nutritional, medicinal and pharmacological properties of Papaya (Carica papaya Linn.). Niscair Online Period Rep 2008;7:364-73.

15. Azarkan M, El Moussaoui A, van Wuytswinkel D, et al. Fractionation and purification of the enzymes stored in the latex of Carica papaya. J Chromatogr B Analyt Technol Biomed Life Sci 2003;790:229-38.

16. Azarkan M, Wintjens R, Looze Y, Baeyens-Volant D. Detection of three wound-induced proteins in papaya latex. Phytochemistry 2004;65:525-34.

17. Pandey S, Cabot PJ, Shaw PN, Hewavitharana AK. Antiinflammatory and immunomodulatory properties of Carica papaya. J Immunotoxicol 2016;13:590-602.

18. Amri E, Mamboya F. Papain, a plant enzyme of biological importance: A review. Am J Biochem Biotechnol 2012;8: 99-104.

19. Khan AV, Ahmed QU, Khan MW, Khan AA. Herbal cure for poisons and poisonous bites from Western Uttar Pradesh, India. Asian Pacific J Trop Dis 2014;4:S116-20.

20. Salleo A, La Spada G, Falzea G, Denaro MG. Discharging effectiveness of lyotropic anions on nematocysts of Pelagia noctiluca. Mol Physiol 1983;6 :19-26.

21. Arillo A, Burlando B, Carli A, Mariottini GL. Mitochondrial alteration caused by cnidarian toxins: a preliminary study. J Biol Res - Boll Soc It Biol Sper 199;70:307-13.

22. Killi N, Mariottini GL. Cnidarian jellyfish: ecological aspects, nematocyst isolation, and treatment methods of sting. In: Marine Organisms as Model Systems in Biology and Medicine (Kloc M, Kubiak JZ eds.). Results and Problems in Cell Differentiation, 65, Springer Nature Switzerland: 2018. pp. 477-513.

23. Kitatani R, Yamada M, Kamio M, Nagai H. Length is associated with pain: Jellyfish with painful sting have longer nematocyst tubules than harmless jellyfish. PLOS ONE 2015; $10: \mathrm{e} 0135015$.

24. Duval C, Cohen C, Chagnoleau C, et al. Key regulatory role of dermal fibroblasts in pigmentation as demonstrated using a reconstructed skin model: Impact of photo-aging. PLoS ONE 2014;9:e114182.

25. Morabito R, Marino A, La Spada G, et al. The venom and the toxicity of Pelagia noctiluca (Cnidaria: Scyphozoa). A review of three decades of research in Italian laboratories and future perspectives. J Biol Res - Boll Soc It Biol Sper 2015;88: 173-78.

26. Borrelli F, Capasso R, Severino B, et al. Inhibitory effects of bromelain, a cysteine protease derived from pineapple stem (Ananas comosus), on intestinal motility in mice. Neurogastroenterol Motil 2011;23:e331.2003.

27. Amini A, Ehteda A, Moghaddam SM, et al. Cytotoxic effects of bromelain in human gastrointestinal carcinoma cell lines (MKN45, KATO-III, HT29-5F12, and HT29-5M21). OncoTargets Ther 2013;6:403. 
28. Yonezawa S, Higashi M, Yamada N, et al. Mucins in human neoplasms: clinical pathology, gene expression and diagnostic application. Pathol Int 2011;61:697-716.

29. DeClerck, M.P., Bailey, Y., Craig, D., et al. Efficacy of topical treatments for Chrysaora chinensis species: a human model in comparison with an in vitro model. Wilderness Environ Med 2016;27:25-38.

30. Chen CF, Chen SM, Chow SY, Han PW. Protective effects of Carica papaya Linn on the exogenous gastric ulcer in rats. Am J Chin Med 1981;9:205-12. 